\title{
The Elastic Edge: A Better Way to Work, Innovate, Create Wealth and Build Your Career
}

\author{
Nicholas Vitalari (Elasticity Labs) \\ Keri Pearlson (KP Partners) \\ John P. Vasellina (CourseConcierge)
}

\section{KEYWORDS: Management.}

From business literature and our own experiences, we all know of exceptional individuals who thrived and made great contributions in a chaotic workplace. But today, chaos and change are a fact of life, especially for entrepreneurs in new ventures, and more employees must be able to thrive and innovate. Businesses face increasing challenges to be agile and elastic in the face of new competition, complexity and change. Many organizations recently have embraced the concept of "elastic enterprises" to make them more flexible and agile and better able to roll with the punches. Ultimately, however, human capital is still the most agile variable in the organizational equation.

We've looked at people who have been able to thrive in dynamic work environments, and the qualities that set them apart. Our perspective, the "Elastic Edge," is based on observations of employees within elastic enterprises, entrepreneurs, and noteworthy leaders who have demonstrated an unusual ability to reframe and reinvent themselves, their companies, and in the process, their careers.

\section{Introduction}

In 2012, our book "The Elastic Enterprise: The New Manifesto for Business Revolution" (Vitalari and Shaughnessy, 2012) chronicled the emergence of a remarkable, new and sustainable model for the enterprise. Elastic enterprises more flexible, could easily adopt new business models, and could grow faster and with less operational friction than the traditional industrial organizations that were the model of business organization for over 100 years. At the time, elastic enterprises were still a novelty. But they have enabled companies like Amazon, Apple, Deere, GE, Google, Tesla and entrepreneurial startups to transform industries and the competitive landscape.
Today, key divisions of established companies and most new startups employ elastic business models. They have allowed new companies -- Uber, Pinterest, Warby Parker, Kickstarter, Trulia, Homeaway, AirBnB -to thrive and grow, and have revitalized companies like GE in their aerospace, healthcare, energy and new industrial Internet business units.

We described their structure and strategy. We identified a new set of skills exhibited by leaders of elastic enterprises. We termed this new style of leadership "Sapient Leadership." Sapient leaders demonstrated a powerful capacity to continually reframe problems, embrace and manage risk, influence and orchestrate more than command and control, and make the boundaries of their enterprises more permeable.

Since then we've learned more. We noticed that our readers not only applied elastic concepts to traditional organizations but also adapted the concepts to their individual work lives and careers. By infusing "elasticity" into their daily lives they realized remarkable results both professionally and personally.

Looking deeper into elastic enterprises themselves, we also found novel work habits. Individuals had to become more open to change, to reframe problems, and "transgress" disciplinary and organizational boundaries. Our sense was that individuals had to up their game to perform in this new elastic setting - a work environment seething with richer and varied information, which in turn, demanded more interdisciplinary solutions.

As we continued our work over the last 30 months, we observed more companies adopting the strategies and structures of the elastic enterprise. We also had the opportunity to talk with individuals working in elastic enterprises and with entrepreneurs, who from the outset employed elastic strategies, structures, and economics 
to launch their startup companies.

Bottom line: Individuals, startups and enterprises large and small are pioneering a new way to work, develop their careers, innovate and create wealth. These employees have rediscovered the pleasures of work and found themselves to be more successful in their chosen career path by developing what we call an "Elastic Edge." Entrepreneurs have found new ways to work as well, and new ways to rapidly launch their companies and galvanize talent to accelerate growth.

In many ways these individuals share a new enthusiasm and mindset that in the past was considered noteworthy and exceptional, perhaps found only in gifted individuals or legendary leaders. But now a growing number of employees and entrepreneurs are reframing what is possible, redrawing the boundaries of initiative, seeking personal growth in volatility, and crafting a new and expanded view of their careers.

\section{Setting the Context}

We are at an early stage in our understanding of the elastic edge. In this paper we recount our present and formative understanding of this newfound operational elasticity at the individual level. Our purpose is to elucidate and reflect on common themes and practices. Our goal is to share preliminary insights based on a small availability sample. We hope that some of the observations might be helpful to those who want to model what we observe in their own work settings. We also want to use this paper to establish an ongoing dialogue about this important development.

The paper begins with a brief overview of the elastic enterprise and its key components to illustrate the unique dynamics that drive new workplace behaviors.

The paper then presents the concept of "the elastic edge," our term for the mindset, role and operating model for individuals who exhibit more elasticity in their work. We position the elastic edge in the context of the organizational realities that drive this new workplace behavior.

The paper then examines several case studies that exemplify the elastic edge mindset. The paper concludes with recommendations for enterprises, leaders, employees and directions for future research.

\section{The Elastic Enterprise}

Elastic enterprises are a new class of enterprise that exhibit a level of strategic, economic, and structural flexibility not previously seen in large scale enterprises. As a result, elastic enterprises display remarkable competitive agility and growth capacity. Five critical dynamics define the new operational capacity of the elastic enterprise:

1. Business Platforms - a formidable combination of technology, software, business logic forming a collaborative and commerce backbone for the elastic enterprise

2. Business Ecosystems - a supercharged business community of partnerships that vastly extends the value proposition offered to customers of elastic enterprises

3. Universal Connectors - powerful technological and process schemes to enable parties of all types to interact electronically with elastic enterprises with low economic friction

4. The Cloud - the global electronic communications and exchange infrastructure for software and services, and

5. Sapient Leadership - six new behaviors exhibited by leaders of elastic enterprises.

Together each dynamic contributes elasticity to the enterprise. In other words, the five dynamics create a greater impact on company flexibility than each dynamic by itself.

For example, the business platform adds elasticity through its technical architecture that enables the enterprise to add or subtract new technological components with relative ease. The business platform also reduces friction and adds elasticity to the process of partnering as it includes all of the necessary business rules, conventions and technical information to enable partners to connect and work together, often without human intervention.

The business ecosystem makes its contribution by attracting and enabling partners and co-creators to build a functioning economic community. With partners and co-creators, an elastic enterprise can rapidly enter new markets with partners who know the markets in ways not possible alone. In addition, products get enhanced and augmented in ways that reflect the partners' market understanding. 
Moreover, because the core products and services are also designed to be elastic, that is, to be enhanced and augmented by others, the value proposition, product relevance and customer choice profile improves with each additional ecosystem partner. Thus an enterprise armed with a business ecosystem provides a greater variety of product options to customers than any predesigned or pre-planned collection of product options could provide alone.

Similarly, each of the other dynamics provide their multiplicative contribution to enterprise elasticity. The Cloud enables more flexible infrastructure options along with a global set of compatible and evolving business services that can be applied as market conditions and opportunities dictate.

Universal connectors further reduce friction through the use of API's, open communication standards, and other architectural standards and position the elastic enterprise to conduct commerce with more customers and work with a greater variety of partners.

As noted earlier, leaders must lead an elastic enterprise differently. Leadership is more open and transparent in elastic enterprises, even after taking into account trade secrets, market strategies, and the need to withhold information for strategic advantage. Yet, stealth considerations aside, Sapient Leaders must cope with a surplus of strategic options generated not only by internal experts, but also from options generated from the prodigious flow of realtime telemetry data, business ecosystem partners, co-creative customers and interested and engaged third party observers. A complete discussion of all five forces may be found in our book.

Elastic enterprises are organizations that are prepared for the future. They have the structure, processes, leadership and technology that provide the flexibility and innovation need for today's dynamic environment. But at the heart of every elastic enterprise are individuals who also exhibit similar characteristics. In the next section, we describe a model that summarizes our thoughts on what we call the elastic edge, and we provide three real life examples of individuals who are successful, in part because of their elastic edge.

\section{The Elastic Edge}

In our ongoing work on the elastic enterprise we noticed that successful employees in elastic companies exhibited a distinctive work style. We noticed it in startups that adopted the elastic model of business. And we noticed certain individuals, in traditional enterprises, that somehow modified and redirected their workplace behavior to respond to organizational movements or behaviors in a more elastic way.

We observed the beginnings of a unique and fresh way to work. The work style was characterized by an orientation toward collaboration, comfort with crossdisciplinary work arrangements, continuous learning, comfort with persistent adaptation and an uncanny faulttolerant resilience built on self-reflection.

Another early observation was unexpected. The day-today process of problem solving and work activities appeared to be more closely tied to the longer-term perspective of career. In other words we observed that the "career" perspective gave these individuals a perspective on their current challenges in the current job. This "career perspective" seemed to convey a greater tolerance for ambiguity, a sense of selfdetermination, greater personal empowerment, a higher awareness of social dynamics and a growth orientation.

Although these initial observations were intriguing, the lack of conceptual specificity and clarity were unsatisfactory. As a consequence we began to gather additional information through more detailed interviews and case studies. To date, the data we have collected is best characterized as an exploratory sample that provides a basic conceptual framework, which, in subsequent studies, can be tested on larger samples. It is this basic conceptual framework and preliminary observations that we will discuss in the remainder of the paper. But first, let's examine how the characteristics of the elastic enterprise give rise to new behaviors.

\section{Enterprise Boundaries Affect Work Behavior}

We suspect that one of the reasons that individuals in elastic enterprises began to reconsider their workplace behavior stems from the way elastic enterprises negotiate their boundaries.

We believe that elastic enterprises force changes in individual and group work behavior precisely because elastic enterprises can more flexibly negotiate their external environment. In so doing, elastic enterprises incorporate many numerous networks of interested 
parties into their principal value networks and their value proposition with customers. As a consequence, elastic enterprises develop elastic boundaries. Specifically, we observe three critical boundary changes that affect work behavior in elastic enterprises:

1. More information interchange occurs at welldefined enterprise-environment boundaries and there are more points across the elastic enterprise where interchange takes place. Hence employees are drawn into more marketrelated issues across a range of internal boundaries within the enterprise.

2. The dynamic between the business platform and the business ecosystem, by necessity, generates greater discourse between business ecosystem participants and the employees of the elastic enterprise. In other words, the platform-ecosystem structure fosters network effects within the business ecosystem and within the elastic enterprise itself. As a result employees must cross internal organizational boundaries, collaborate frequently and establish a new appreciation for other functional disciplines in the mutual pursuit of market objectives.

3. The confluence of business ecosystem partners, co-creative customers, and real time market telemetry conspire to generate prodigious amounts of data about product and service performance, detailed clinical data on product use, and unmet customer needs. As a consequence employees must process that data and work with others to make sense of the data and take action.

The three changes in boundary behavior, in turn, drive a greater need for internal coordination and collaboration within the elastic enterprise. Less obvious, however, is the effect on the traditional departmental and functional structures and loyalties. We find that the nature of the elastic enterprise forces individuals and teams to embrace, foster and support a more fluid interdisciplinary environment.

More specifically, our experience with elastic enterprises notes a greater use of cross-disciplinary teams to appropriately respond to the increased flow of information due to its complexity and requisite variety.

Three elastic companies support these observations.
The first company provides third-party evaluations of products and services in an industrial sector. A key part of the company's service structure is to monitor the customer's real-time experience with their information products on the web and on mobile devices. The company's monitoring system provides a stream of realtime information on various dimensions of the customer's online experience.

To meet service and customer satisfaction metrics, they field an interdisciplinary team that includes experts from marketing, sales, IT, operations and finance. Often this team must design operational fixes, surface potential new service features to meet unmet customer needs or escalate potential options to upper levels of management. This team often sees new market trends and service deficits before anyone else in the enterprise. These internal employees now work at the boundary of the organization with data and on issues that were not previously part of their responsibilities.

The second company serves the hospitality sector. Due to the information-intensive nature of their products and services, the increased information flow quickly finds its way into the core of their software development organization. As with the first company, this information flow contains elements that go far beyond a technological fix or adding a new software function. The head of development has had to move to a much more fluid development organization structure, one the permits greater collaboration within development and additional collaboration with other non-IT internal units. Again, because the solutions require fast interdisciplinary solutions, the dev team must jointly solve problems and employ a broader community of individuals to effectively meet market demands. In turn, this has changed the way that individuals view their jobs, work with others and appreciate other functional knowledge.

Similarly, the manufacturing division of a pharmaceutical company learned that to be elastic forced them to "turn themselves inside out." Previously experts were behind the scenes or behind the curtain. No longer. "Internal experts" had to be visible and available for customer selling situations. Furthermore, they were called upon to observe and gain insights into potential new requirements and future product paths. However, the company found that some experts declined such roles whereas others who volunteered were inadequately prepared. Only a few had the interest 
and flexibility to embrace the challenge.

\section{Elastic Strategic Imperatives Affect Executive Work Behavior}

Nor are the new demands and opportunities in work behaviors limited to the rank and file or professional and technical ranks.

The new crucible of the elastic enterprise shapes individual work behaviors for executives as well. Elastic enterprises are strategic options generators (c.f. Vitalari and Shaughnessy, 2012). We introduced the concept of the strategic options portfolio to describe the collection and evaluation of a new and prolific stream of strategic opportunities generated by business ecosystem partners and real-time customer usage information of the products. We noted that such strategic realities drove elastic enterprises to adopt what we called an active strategy process, wherein, strategic options were considered on a continuous basis, rather a more familiar episodic strategy timetable.

In discussions with senior executives in elastic enterprises we noted that many were overwhelmed with prodigious stream of new product and service ideas. During a multi-company seminar, one executive remarked that it was very difficult to match the internal decision processes of the executives and their time constraints with the rapid pace of new product ideas and directions.

Executives from multiple companies indicate that elastic operations change the speed of decision-making throughout the organization, and also reorient employees and executives to eschew the insularity of the traditional "not-invented-here" viewpoint on innovation. As a consequence, each employee and leader must be ready to reassess their strategy and pivot when necessary, and often, to accelerate their deliberation and decision processes.

Clearly, the elastic enterprise poses many new work requirements that are too numerous to fully outline in this paper. Nonetheless, we have been able to synthesize the main responses and characterize the new elements of the employee mindset that we call the elastic edge.

Labor markets and job listings provide some additional support for our observations. Workers who exhibit a mindset that embraces change and adaptation are hotly sought after, whether they work on the shop floor, as a middle manager or as an executive. And make no mistake, as markets evolve to embrace greater differentiation and customization in the 21st century, a greater number of the occupations will be forced to consider greater interdisciplinary collaboration -- and employees that have a sense of joie de vivre -- in midst of a workplaces continually punctuated with differentiation and change.

\section{The Elastic Edge Framework}

Our notion of the "elastic edge" emerged from what we observed directly, indirectly and through secondary accounts. We have taken what we have learned from our ethnographic observations and developed a framework of the key elements that appear to be associated with successful work performance in elastic enterprises. These elements also apply to individuals who might not operate in an elastic enterprise, but who exhibit greater levels of elasticity in their work behaviors and career within more traditionally structured settings.

Individuals that operate with an elastic edge exhibit five distinct behaviors. These behaviors also appear to represent an orientation toward their workplace and their careers. We have been tempted to consider these components as purely cognitive in orientation. However, while each component has a cognitive element, the strong orientation to action in these individuals motivated us to characterize these five components more broadly as behaviors.

The elastic edge has five components (see Figure 1):

1. Operate from a Pivot Point. Maintains a 360 view of options and can move in whatever direction is best for them at that point. Think about a basketball player who stops dribbling, plants the toe of his shoe on the ground and looks all around for the best place to pass the ball. He or she is pivoting. In today's business world, with everything happening so quickly, those with an elastic edge have a way of pivoting as things change around them.

2. Seize Radical Adjacencies at Work. People with an elastic edge not only look around but they have the ability to "do" the next thing, even if requires them to stretch beyond their disciplinary comfort zone. They move to the next 
opportunity with low friction, and are not limited by their 'core competencies.' Often those with an elastic edge are most impressive when they go that 'extra mile' to gain the new skills or connections necessary to make the change they seek. We suspect that the strong desire to learn and expand their impact is at the foundation of this behavior.

3. Act as a Universal Connector: They have a way about them that allows them to establish a productive working relationship with anyone and expand the social network for everyone. They naturally seek ways to add value or be productive in relationships. At a behavioral level, we see those with an elastic edge fluidly speaking multiple languages: those of business, those of IT, those of finance, etc.

4. Think with an Elastic Mindset. We have noticed in our work that people with an elastic edge have elements of a growth (rather than fixed) mindset (See Dweck, 2008). In addition, the elastic edge also has another component. The elastic mindset focuses on problem finding, problem definition, and then the generation of new solutions. We find this generative thinking as a key component of being elastic. Those with an elastic edge cognitively construct a set of opportunities in their mind that help them address any opportunity they encounter. They do not let themselves be limited by their past experiences, and they seek challenges just for the fun of successfully mastering them.

5. Be a Catalyst. To be a catalyst means to precipitate an event or an action. People with an elastic edge make things happen. Their presence and involvement starts a chain reaction of activities, thoughts and feelings that move an organization forward. They want to see action and movement. Without them, things just take longer or never happen.
Figure 1: The Elastic Edge Framework

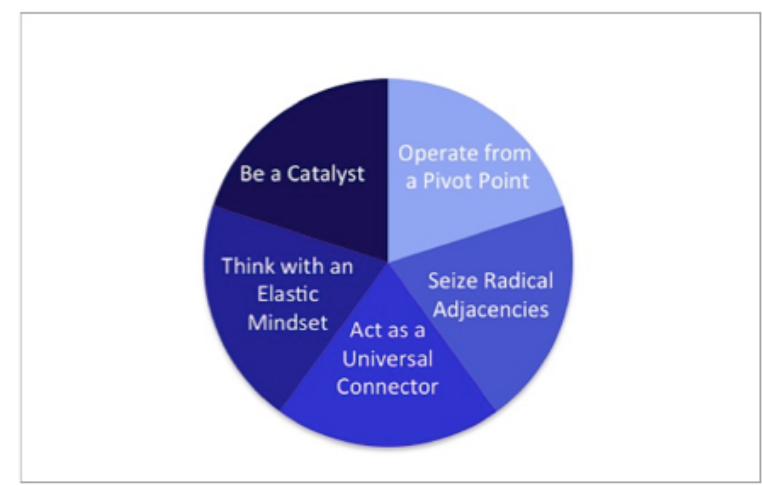

\section{Illustrative Case Studies}

We use three case studies to illustrate the elastic edge in action:

1. Howard Schultz
2. June Drewry
3. Stephanie Louie

\section{Howard Schultz: A Leader with an Elastic Edge}

Howard Schultz, by any definition, epitomizes an individual who has developed the capacity to flex, adapt and lead under dynamic market conditions. Schultz is an entrepreneur, a marketer, a seasoned executive, and an industry transformer. Consider that Starbucks rapidly developed its global presence without the traditional marketing approach usually seen in retail establishments, restaurants, or packaged goods companies. Today, Starbucks operates as a powerful player that expanded rapidly from its local roots as a coffee roaster in Seattle to a global presence in virtually every country worldwide with a full complement of consumer goods.

Also consider that Shultz has re-invented himself at least three times, most recently in 2012 . We see many parallels in legendary leaders and entrepreneurs, like Howard Schultz and in those with an elastic edge.

How did Shultz do it? Hard work? Sure. Strategic excellence? Absolutely. But we believe that Howard Schultz has an elastic edge - an edge that provides him with elasticity in decision-making and the capacity to maneuver under uncertainty.

Early in his career, Schultz demonstrated the ability to pivot, to exploit radical adjacencies, and be a catalyst. 
Schultz came from humble beginnings, growing up in a public housing project in Brooklyn, New York. Today Schultz is worth an estimated \$2.2 Billion. Anyone who has seen him in person or in interviews immediately notices his enthusiasm not just for Starbucks, but also for people. Starbucks spends more on health insurance per year than on its main ingredient in its products coffee. Why, because Schultz remembers his beginnings and offers health insurance to part-time employees and full-time employees at Starbucks.

Before Starbucks, Schultz worked as sales person at Xerox. His next job brought him into the coffee industry with Hammarplast, housewares company. He was intrigued because the small, local Starbucks Coffee Company bought a lot of coffee makers. Schultz later remarked that when he entered Starbucks, he felt at home (Schorn, 2006). The rest is history.

Schultz soon became Director of Marketing for Starbucks. At the time Starbucks was in the coffee roasting and sales business. He wanted to add espresso bar to the business model. While the saw the opportunity to expand into the coffee business, the current owners of Starbucks did not, even after a successful pilot project.

So Schultz left Starbucks (pivot), looked for investors (catalyst), opened his first store (radical adjacency), and one year later bought the retail business from Starbucks for \$3.8 million (elastic mindset). In 1992, Starbucks had its initial public offering (IPO).

But, Schultz's ability to reinvent and be elastic did not stop there. In 2000, Schultz retired from Starbucks to focus on other interests and philanthropic activities. In 2008, Howard Schultz returned to Starbucks (pivot), after a brief retirement to repair a poorly performing Starbucks Corporation. He made tough decisions, including layoffs, store closures, significantly restructured the company, and expanded into new markets (catalyst). Within 24 months of Schultz's return, Starbucks was in growth mode again (elastic mindset) and growing in newly entered markets (tadical sdjacency).

In 2012, Howard Schultz announces that he would cede operational CEO responsibilities (pivot), restructure executive management roles (catalyst) and focus on a new and game-changing business opportunity for Starbucks in electronic payments (radical adjacencies)
Howard Schultz shifted from an advocate for baristas to an advocate for proven service principles for customer service and international markets. The revitalized, postretirement Starbucks is now becoming an elastic enterprise and has pioneered a sophisticated social network and branded community of loyal customers that form a powerful Starbucks business ecosystem and now fuels Starbucks vaunted electronic payment system. Perhaps it is little wonder that Starbucks, once simply a location-based retailer is also an elastic enterprise with growing "terrestrial world" and "digital world businesses," as well.

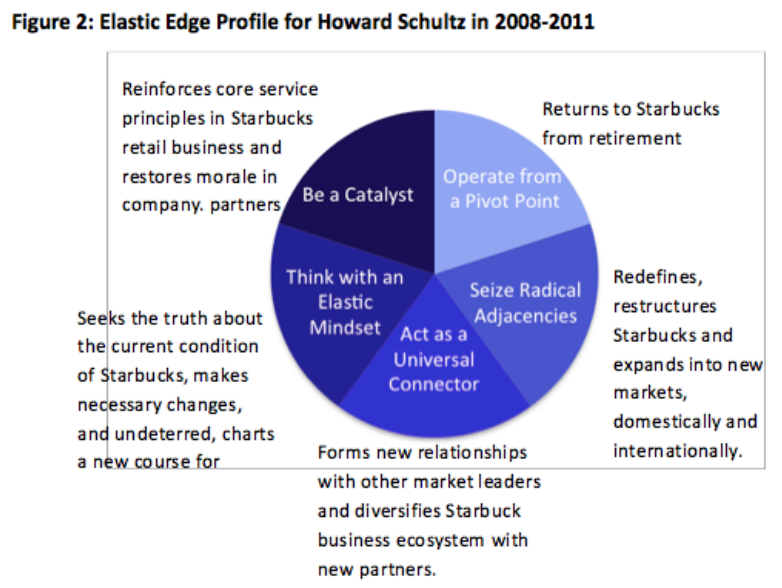

\section{June Drewry, A Proven Executive with an Elastic Edge}

June Drewry is an accomplished business executive, executive coach and board member with experience in multiple Fortune 500 companies,. However, while she has guided the technology strategy for many traditional corporations, her approach to work and her career exhibit characteristics of an elastic edge.

We spent time with June to better understand her approach to the work environment and her perspective on how to be opportunistic, remain flexible, and lead in a way that catalyzes others to be their very best.

When asked about her career, June jokingly says "she can't hold a job." But the real story is that June's strength is in her ability to pivot, to be a catalyst and to be a universal connector. June spent much of her career as an information systems executive in the financial services industry. She was the $\mathrm{ClO}$ of Asset Accumulation SBUs at Aetna in the early 1990s, and then moved to President of one of the wholly owned subsidiaries of Aetna, building on her executive 
experience but pivoting to a new role. She later took on executive roles at Lincoln National Financial Services, Aon Corporation, and Chubb.

Figure 3 summarizes June's outlook on her career steps, as framed by the five characteristics in the elastic edge model. More recently, June is a sought after consultant, coach and executive advisor, helping newer IT executives develop these same characteristics. June believes that to be a successful executive in today's dynamic environment, one must be flexible, always looking around to see what the best path will be to the goal, while being a people person who makes things happen.

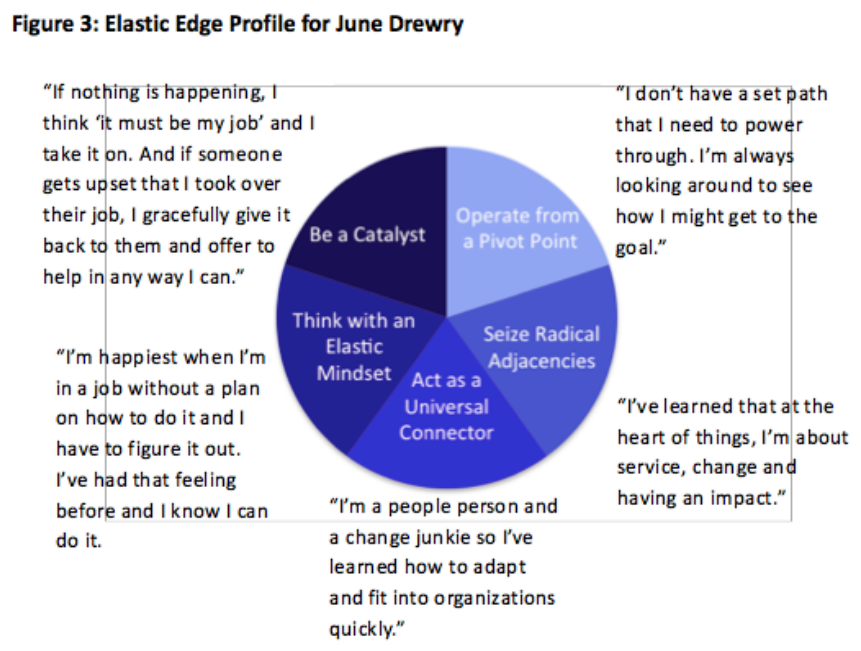

\section{Stefanie Louie: A Young Leader with Tremendous Potential}

The elastic edge isn't limited to executive and those with lots of experience. A generation of employees has now grown up in an elastic world. Although still somewhat early in her career, Stefanie Louie is a stellar example of young person with the elastic edge.

Stefanie entered the workforce in 2004 after graduating from U.C. Berkeley with a degree in psychology. Her first job was an entry-level position at an insurance company in Sacramento processing worker compensation claims. After nearly a year, she relocated and took a contract position in an Environment Health \& Safety group at a biotech company. It wasn't long before she was hired as a full time employee on the Drug Safety team where she thrived for many years before assuming her current role as a Compliance Manager.

What gives Stefanie the elastic edge is not the historical sequence of her positions. Her edge comes from the manner in which she operated in each role that allowed her to consistently receive excellent performance reviews, add value to the company, and ultimately reinvent herself through a series of pivots and contributions throughout her career.

While working the in the Drug Safety group in 2006, Stefanie helped to create an Employee Affinity Group focused on developing leadership skills of employees new to the workforce. As a member of this group, Stefanie built a mentoring program that connected company executives with millennial employees.

Stefanie's ability to recruit executive mentors was uncanny and largely due to her ability frame the value proposition using language that resonated with each leader's area of interest and expertise. Stefanie also engaged in other activities that helped her expand her knowledge of the business including rotational assignments, special projects, and volunteering to facilitate sessions of the New Employee Orientation program to help build presentation skills.

But Stefanie's story didn't stop there. After several years on the Drug Safety team, she pivoted, and is now a Compliance Manager. She sees her current role as an "opportunity to partner with her clients, rather than simply enforce rules".

Stefanie continues to succeed in her role, but what gives her the elastic edge is what happened next. As a new mother, Stefanie saw the challenges many employees were having managing the demands of their personal and professional lives. She observed when people got busy, the first activities they stopped doing were the ones that would help them the most including exercise, doctors appointment, and healthy eating.

To remedy this, Stefanie designed an app for her group that reinforced the wellbeing of her team members. With the app team member could earn points for completing healthy activities and redeem them for prizes. Stefanie and her teammate secured funding from her department to develop the idea further, and she is currently collaborating with the internal IT staff to create a the app.

Stefanie is a prime example of a person with the elastic 
edge. By employing an elastic mindset, she is able to rapidly learn new things, and add value to the company and the people around her as she goes above and beyond to quench her thirst for learning.

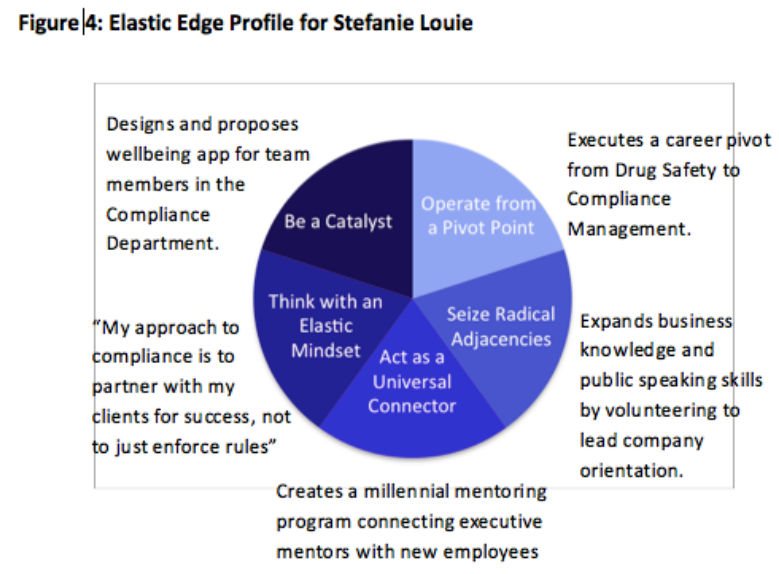

\section{Discussion}

Our examples provide three very different stories about individuals with an elastic edge. All three have the similar stories about career decisions they have made, and personal philosophies that drive their actions and, ultimately, their success.

\section{Pivots}

Operating from a pivot point injects new degrees of freedom into workplace behaviors. The ability to reframe a situation, pivot to gain perspective and act essentially expands options for the employee or entrepreneur.

Reframe-pivot-act is analogous to a kata in martial arts. Over time it becomes a rehearsed, choreographed pattern that due to its lack of specificity can be applied in many situations. In addition, the reframe-pivot-action sequence is not simply a cognitive sequence it is linked to purpose driven behavior.

For example, June noted that she does not immediately set a firm path, but rather looks around to see what the options are and then takes the best one. Similarly, we see a repeating pattern in Schultz's career of reinvention in building the business or seizing a new opportunity. Stephanie, while earlier in her career than Schultz or Drewry, illustrates similar approaches in making innovative moves in her company.

Although we did not observe it, the use of a pivot point may also contain within it the ability to gracefully move back to the pivot point without significant cost. In other words, the role of the pivot point in workplace resilience may be worth further investigation.

\section{Adjacencies and Radical Actions}

All three individuals work outside of their comfort zone when the need arises. Clearly, Schwartz learned to do this early in his life to solve the problem of being poor. Clearly radical movement continues today as he relinquished his CEO position to focus on a new opportunity in electronic payments.

Drewry has made radical moves as well. Her focus on service, change and having an impact drove her to thrive on doing new things. Over her career she has expanded her responsibilities and has stepped into new roles as a leader in professional associations, volunteer work, or more recently as an executive coach. Stephanie saw the problem of workplace well being and the issues of lifestyle conflicts and took the initiative to design a new app.

It is interesting to note that seizing a radical adjacency seems to be made possible by the reframe-pivot-action pattern discussed earlier. It is difficult to imagine a situation where someone would make a radical move, out of one's comfort, zone without due consideration. However, due consideration can sometimes stymy action. But, an individual that uses the pattern of reframe-pivot-action as a matter of course develops the habit of looking at options and thus may be more prone to taking action.

\section{Being a Universal Connector}

In an increasingly connected and social world where strong and weak ties prove valuable, operating as a universal connector generates social capital. Collaborative attitude, and an appreciation for other's expertise enabled these leaders to leverage their capabilities into something bigger.

In each of three case examples, we observe universal connector behavior. Schultz, Drewry, and Louie, make connections in their work and use those connections to move the organization forward.

We believe some other elements underlie the universal connector behavior we observed. One of the significant problems within human organizations is the ability to be inclusive. Inclusiveness essentially elevates diverse 
talents, strengths and disciplinary expertise above organizational boundaries or disciplinary loyalty.

Dynamic environments require interdisciplinary solutions, interdisciplinary teams, and the ability to merge integrative thinking (Martin, 2007). We suspect that universal connector not only builds social capital and social networks, but also builds an appreciation of tacit and disciplinary knowledge in others and openness to collaborative activity.

\section{Elastic Mindsets}

The oft heard phrase, "failure is not an option," while dramatic, is often not helpful. Ironically, as Dweck (2008) has pointed out, the fear of failure or the avoidance of failure often reduces performance and increase the probability of failure.

The elastic mindset is essentially a mindset of possibilities and options. Those with an elastic edge consider what could be, rather than the obstacles that stand in the way what could be.

Individuals with an elastic edge have a take-charge and can-do approach. Interestingly they seldom do it alone. Each of our examples did not shy away from taking the initiative to make things happen. Schwartz left Starbuck only to buy it a year later. He was not deterred by the recalcitrance of management.

In our discussions with Drewry we found a similar mindset. She recounted a situation where she was hired to help develop the next Chief Information Officer. Although never having been hired specifically to do that in her previous roles, she accepted the challenge. She then worked to learn all she could learn about the organization's culture, the junior executives who were candidates for this top job, and the needs of the business. From that base of knowledge she was equipped to assist the company in their succession plans.

Similarly, Louie transformed her approach to compliance. By reframing the problem and intensively collaborating with others, the "new compliance" went beyond the enforcement of rules to a service organization focused on solving problems and creating value. Rather than allowing rules to become a closed system of obstacle, her focus became one of generating options and possibilities.

\section{Catalytic Effects}

What does it mean to be a catalyst and why is it important in a dynamic workplace?

It seems that being a catalyst is about leverage and learning. Many human situations, organizational and otherwise, prove intractable. Personal perspectives, blind spots, time and resource constraints, or a host of other problems stultify progress or result in missed opportunities. In environments where dynamism is a constant, the lack of movement and growth can be costly and in some cases catastrophic.

In our observations we noted that individuals with an elastic edge have a never-ending thirst for learning. Sometimes that manifests itself by taking on new roles as seen with Schwartz with his many roles at Starbucks. But learning without action in a workplace creates little value if it cannot be applied.

Drewry commented that a resume with a number of roles does not mean that one cannot hold a job. Instead it could mean that they learn what they can at one role, and then apply it to the next role, while learning all there is to learn in the new role. On a cumulative basis they then can offer more to help move an organization forward. Thus learning and experience becomes a powerful lever for action.

Consider that Drewry does not hesitate to tackle a problem if she sees the problem, determines it needs to be solved, even though it is outsider her area of responsibility. She has the confidence to take it on. In doing so she moves the organization forward.

Similarly, Louie operates with a similar pattern. See the problem, understand it, look for solutions, learn about apps, and find the resources to make it happen. In the process she becomes a catalyst (or lever) that moves the organization forward and creates value where none existed before.

To be catalytic requires confidence, but that confidence is based on problem finding, research, and a desire to create value. It also depends on curiosity and the desire to learn. We see this desire to be a catalyst as a key behavior for success in dynamic workplace environments found in elastic enterprise and entrepreneurial startups.

\section{Implications}


The dynamic environment in which organizations find themselves today is the "new normal." Coping with constant change requires organization structures that are fluid, flexible and elastic. But most importantly, it requires people who provide a new way to view work and get things done while maintaining a collegial and collaborative work environment.

Individuals who exhibit an elastic edge bring an attitude that differentiates them from the others who want to continue to do the same thing over and over, because it worked in the static past. Individuals with an elastic edge not only steer their organizations through dynamic environments, but they also regularly seek opportunities where they can grow and still contribute to the overall success. The elastic edge can be cultivated in any individual, but it the successful executive of tomorrow's organizations must certainly have it.

We believe that to be a successful entrepreneur and deal with the twists and turns of a startup requires an elastic edge. Most successful entrepreneurs exhibit the five behaviors we have noted. However, entrepreneurs and startups require employees and partners who exhibit the elastic edge too. We have observed situations where entrepreneurs simply assume that all people have these skills. The elastic edge framework should remind entrepreneurs to assess whether prospective hires have an elastic edge. Some startups find later that some of the founders may not have an elastic edge, and this create conflicts and problems as the startup gains traction in the marketplace. We suggest that entrepreneurs consider the elements of the elastic edge when evaluating not only founders and hires, but also in selecting funding sources and strategic partners.

While this work is exploratory, it suggests many new areas for work and the need for additional research. All organizations must consider the demands of a dynamic workplace driven by new types of boundaries and the confluence of multiple networks of collaborators. For example, the head of a startup company may need to pay special attention to early hires and whether they are capable of operating with the necessary flexibility, pivoting or reframing dynamic situations. Similarly, the CEO of a large corporation and their head of HR many need to survey individual and collective capacities of its workforce to adapt, operate and challenge existing structures and processes in the workplace.
The study reinforces the continued study of the changing nature of organizational boundaries. In particular, this study suggests further examination of the skills and behaviors of individuals as they ply their way across those new types of boundaries, at different times and as part of different networks of actors, including customers. The study also suggests that the individual's perspective and tacit knowledge of the work "terrain" (the actors, partners, multiple cultures, etc.) play an important role in understanding collaboration in dynamic workplaces. It also seems that large enterprises must consider whether their current culture and policies stifle individuals who have an elastic edge and whether their workplaces have the right work arrangements to support the elastic edge.

Finally, it's not surprising that individuals who exhibit the elastic edge also bear a strong resemblance to successful leaders. In our opinion, all companies have an opportunity to win by encouraging elastic edge behaviors, at this early stage. In the process they will better serve the market and spur a new generation of adaptive employees and a cadre of potential leaders.

\section{References}

Alin, P., Iorio, J. and J. Taylor, "Digital Boundary Objects As Negotiation Facilitators. Project Management Journal, 44(3), 48-63.

Carlile, P.R, "Transferring, translating, and transforming: An integrative framework for managing knowledge across boundaries. Organization Science, 15(5), 555-568.

Dweck, C.S., Mindset: The New Psychology of Success, Ballantine Books Trade Paperback, Edition, Random House, New York, 2008.

Jarvenpaa, S. L., and Leidner, D. E. (1999). "Communication and trust in global virtual teams." Organization Science, 10(6), 791-815.

Martin, Roger, The Opposable Mind, Harvard Business School Press, Boston, MA, 2007.

Schorn, D. "Howard Schultz: The Star of Starbucks," 60 Minutes, April21, 2006, http://www.cbsnews.com/news/ howard-schultz-the-star-of-starbucks/3/.

Vitalari, N. and Shaughnessy, H., The Elastic 
Enterprise: The New Manifesto for Business

Revolution, Telemachus Press, 2012. 